\title{
Knowledge and Practice of Pregnant Women regarding Prevention of Iodine Deficiency during Pregnancy
}

\section{Wessam Ramadan Hassan ${ }^{1}$, Doaa Mohamed Sobhy El- Sayed ${ }^{2}$ and Hedya Fathy Mohy El- Deen $^{3}$}

(1) Nursing Specialist, Shebine El-Kanater Centeral Hospital, Egypt and (2, 3) Assistant Professor of Community Health Nursing, Faculty of Nursing, Benha University, Egypt

\section{Abstract}

Background: Iodine is an essential trace element for normal growth and development of fetus body. Iodine deficiency disorder is one of the most important preventable micro nutrition deficiency problems globally. Aim of the study: Was to assess pregnant women knowledge and practice regarding prevention of iodine deficiency during pregnancy. Research design: A descriptive research design was used in carrying out this study. Setting: This study was conducted at pregnant follow up clinic at Medical Center at Benha City, Qalubia Governorate، Egypt. Sample: Simple random sample was used in this study. The total sample included 337 pregnant women. Tools of data collection: One tool was used; an interviewing questionnaire which contained three parts. Part I: Socio-demographic characteristics of pregnant women. Part II: Pregnant women knowledge about A): Iodine deficiency, B): Nutritional sources of iodine. Part III: Reported practices of pregnant women regarding iodine deficiency. Results: $31.8 \%$ of pregnant women had poor knowledge about iodine deficiency during pregnancy and 55.2\% of them had unsatisfactory practices regarding iodine deficiency. Conclusion: There was statistically significant relation between total knowledge score of studied pregnant women and their age and income. There was statistically significant relation between total practice of studied pregnant women and their total knowledge. Recommendation: Health educational program should be developed and implemented for pregnant women about iodine deficiency during pregnancy and booklets should be available and distributed in all maternal and child health care centers and in all hospitals for prevention of iodine deficiency.

Keywords: Iodine deficiency, Knowledge, Practice, Pregnant women, Prevention

\section{Introduction}

Iodine is a key component for the synthesis of thyroid hormone and is especially crucial in pregnancy and early life due to influence on brain development of the fetus and infant. Iodine deficiency leads to a spectrum of disorders namely iodine deficiency disorders including cretinism, increased pregnancy loss, infant mortality, intellectual impairments, growth retardation, and thyroid dysfunction with or without goiter (Zimmermann \& Boelaert, 2015).
Pregnant and lactating women are particularly vulnerable to iodine deficiency disorders because of increased iodine requirements during pregnancy. Iodine intake is essential for the production of thyroid hormone. Iodine deficiency remains a public health problem in many regions around the world. Iodine deficiency can present as a spectrum of disorders depending on the degree of severity. Universal salt iodization has been shown to prevent iodine deficiency disorders in severely iodine deficient areas (Diaz et al., 2020). 
Iodine in food and iodized salt is present in several chemical forms including sodium and potassium salts, inorganic iodine, iodate, and iodide. Iodine rarely occurs as the element, but rather as a salt. For this reason, iodine is referred to as iodide and not iodine. Iodide is quickly and almost completely absorbed in the stomach and duodenum. Iodate is reduced in the gastrointestinal tract and absorbed as iodide. When iodide enters the circulation, the thyroid gland concentrates iodide in appropriate amounts for thyroid hormone synthesis and most of the remaining amount is excreted in the urine (Bonofiglio\& Catalano, 2020).

Swelling of the thyroid glands in the neck can cause a visible lump, called a goiter. Hypothyroidism typically causes symptoms that can include fatigue, increased sensitivity to cold, constipation, dry skin, weight gain, puffy face, muscle weakness, elevated blood cholesterol levels, pain or stiffness in the muscles and joints, slowed heart rate, thinning hair, depression, poor memory and a heavierthan-normal period in menstruating women. In infants hypothyroidism is likely to cause symptoms like frequent choking, large tongue, puffy face, constipation, poor muscle tone and extreme sleepiness. In children and teens, this condition may cause poor growth, delayed tooth development, delayed puberty and poor mental development. Cognitive issues symptoms can include low intelligence quotient, trouble learning and mental disabilities especially in children (Raman, 2017).

Untreated iodine deficiency can lead to severe hypothyroidism. Complications may include heart disease and related disorders, such as an enlarged heart and heart failure, mental health issues such as depression and cognitive impairment, damage to the body's peripheral nerves, known as peripheral neuropathy, impaired ovulation, which may cause infertility in women, Low amounts of thyroid hormone in pregnant women can increase fetus's risk of birth defects. Pregnancy-related issues that iodine deficiency can cause include miscarriages, stillbirth, preterm delivery, congenital abnormalities in newborn and In severe cases, iodine deficiency can cause a condition called cretinism (Ferguson and Dimitri, 2018).

Iodine Deficiency Disorders (IDD) represents all the negative health consequences of low iodine intake on the growth and the development, which could be totally prevented by adequate iodine intake (Ivanova, 2015). By 2017, 85\% of the African countries had achieved sufficient iodine nutrition in the general population. However, only four of the eleven African countries that had median pregnancy survey data South Africa, Tanzania, Sierra Leone and Ghana had adequate iodine intake during pregnancy and five Burkina Faso, Egypt, Niger, Morocco, and Senegal had insufficient intake during pregnancy, while Djibouti and Liberia had more than enough iodine intake during pregnancy (Iodine Global Network, 2017).

Community Health Nurses (CHNs) have an important role in preventing iodine deficiency during pregnancy through providing health education about iodine, supplementation, food rich with iodine and importance of having sufficient iodine during pregnancy. CHNs Provide sensitive care for women with iodine deficiency through early diagnosis and proper treatment. Early detection of iodine deficiency is essential to prevent health consequences. Early detection of disease is mainly based on medical examination. Also prevention of complication of iodine deficiency is important (Kumar et al., 2020). Iodine deficiency in pregnant 
women can be improved by appropriate nutrition during pregnancy. Besides, controlling maternal iodine deficiency is important to prevent neonatal complications such as preterm delivery (Gargari et al., 2020).

\section{Significance of the study}

Pregnant, lactating women and children are the most vulnerable group to IDD. Studies done in Egypt over last half century revealed that IDD is prevalent in most governorates of Egypt constituting a major public health problem, with varying degrees of severity. It ranged between severe public health problem in New Valley and some governorates of Upper Egypt to mild/moderate in others. About one third (28.8\%) of pregnant women had iodine inadequate intake. Iodine inadequacy was prevalent among pregnant women based on their dietary intake. Intake of dietary supplements containing iodine during pregnancy is recommended, with regular follow up of iodine status for pregnant women (Ragab et al., 2019).

\section{Aim of the study}

The aim of this study was to asses knowledge and practice of pregnant women regarding prevention of iodine deficiency during pregnancy.

\section{Research question}

- What are pregnant women knowledge and reported practice regarding prevention of iodine deficiency during pregnancy?

-Is there a relation between pregnant women knowledge and their reported practice regarding prevention of iodine deficiency during pregnancy?

-Is there a relation between demographic characteristics of pregnant women and their knowledge and reported practice regarding prevention of iodine deficiency during pregnancy?

\section{Subjects and Method}

\section{Research design:}

A descriptive research design was used in carrying out this study. Adescriptive approach provides descriptions of experiences and practice particularly in areas where little is known about the topic under investigation. This is particularly relevant in nursing and health care research, which is commonly concerned with how pregnant women experience illness and associated health care interventions.

\section{Setting:}

The present study was conducted at pregnant follow up clinic at Medical Center at Benha City, Qalubia government. This center characterized by high attendance rate of pregnant women.

\section{Sampling:}

Simple random sample was used in this study. According equation $\mathbf{n}=\frac{\mathbf{N}}{\mathbf{1 + N} *(\mathbf{e}) \mathbf{2}} \mathrm{n}=$ the sample size, $\mathrm{N}=$ the population size, $\mathrm{e}=$ the acceptable sampling error (Polonia, 2013). The number of pregnant women attending to the previous mention setting 2168 over the year of 2018. The total number of selected sample equal 337.

\section{Tools of data collection:}

One tool was used in this study that consists of three parts of an interviewing questionnaire sheet: The researcher designed questionnaire based on literature review, approved by supervisors and it was written in simple clear Arabic language.

\begin{tabular}{llr} 
Part I: & \multicolumn{2}{c}{ Socio-demographic } \\
characteristics of & studied pregnant
\end{tabular}


women it composed of 5 questions about; age, residence, educational level, occupation and family income.

Part II: It was concerned with knowledge of pregnant women about iodine deficiency. This part included two items:

A) Knowledge of studied pregnant women regarding iodine deficiency, it composed of 10 questions.

B) Knowledge about nutritional sources of iodine it composed of 6 questions.

\section{Scoring system:}

The scoring system for pregnant women knowledge was calculated as follows (2) score given when the answer was complete correct answer, (1) score was given for incomplete correct answer, and (0) score was given for incorrect answer or don't know. The scores of items were summed-up and the total divided by the number of the items, giving a mean score for the part. These scores were converted into a percent score.

The total knowledge scores were (32 points) which represent $100 \%$ and categorized into three levels as following:-

- $\operatorname{Good} \rightarrow$ when the total scores was $\geq$ $75 \%(\geq 24)$.

- Average $\rightarrow$ when the total scores were $50 \%$ to less than $75 \%$ (16 to < 24).

- Poor $\rightarrow$ when the total scores was less than $50 \%(<16)$.

Part III: It was concerned with reported practices of pregnant women about prevention of iodine deficiency. It composed of (5 items) about using and consumption of food and supplementation rich with iodine.

\section{- Scoring system:}

A score for each answer on questions of reported practice was given as follow:

- $2=$ Always

- $1=$ Some times

- $0=$ Never

Total score of reported practice $=10$

The practice was considered satisfactory if the score of total practice $\geq 75 \%(\geq 7.5)$ and considered unsatisfactory if it $<75 \%(<7.5)$.

\section{Content validity:}

The tools validity was done by five Staff Nursing Experts from Community Health Nursing in Benha Faculty of Nursing who reviewed the tools for clarity, relevance, comprehensiveness, and applicability.

\section{Reliability of tools:}

The reliability was done by Cronbach's Alpha coefficient test which revealed that each of the two tools consisted of relatively homogeneous items as indicated by the moderate to high reliability of each tool. The internal consistency of knowledge was 0.713 and practice was 0.623 .

\section{Ethical considerations:}

Permission has been obtained orally from each mother before conducting the interview and given a brief orientation to the purpose of the study. They were also reassured that all information gathered would be confidential and used only for the purpose of the study. No names were required on the forms to ensure anonymity and confidentiality. They were also informed about their right to withdraw at any time from the study without giving any reasons.

\section{Pilot study:}

The pilot study was carried out on $10 \%$ of the sample size who represented 34 
pregnant women. The pilot study was aimed to assess the tool clarity, applicability and time needed to fill each sheet, completing the sheet consumed about 15- 20 minutes. No modifications were done, so the pilot study sample was included in the total sample.

\section{Fieldwork:}

The data was collected from pregnant women who attended in the previously mention setting through the interview with them. Collected data was conducted at a period of 5 months which started from the beginning of September 2020 to the end of January 2021. The investigator was attended two days/ week for Medical Center from 9.00 AM. to 12 MD., those days were (Monday \&Thursday) to collect data because this days characterized by highly attendance rate of mother, the average number of interviewed mothers was between 8-9 mothers/day depending on their responses to the interviewers, each interviewed mother takes about 15 to 20 minutes to fill the sheet depending upon their understanding and response.

\section{Statistical analysis:}

Computerized data entry and statistical analysis were fulfilling scored using Statistical Package for Social Science (SPSS), version (22). Descriptive statistic was first applied (frequency, percentage) then other statistical test such as, Chi-square and using mean and stander deviation.

The correlation- coefficient was used (r).

Statistical significance was considered at:

- Significant result when P- value < 0.05 .

- Highly significant result when Pvalue $<0.001$.

- Non- significant result when Pvalue $>0.05$.

\section{Results:}

Table (1): Shows that; $65.3 \%$ of pregnant women aged 20 years to less than 30 years with mean age \pm SD $31.2 \pm 5.22,60.8 \%$ of them were lived in rural areas while $37.3 \%$ of them had basic education, $59.1 \%$ of them were employee and $41.5 \%$ of them had enough income per month.

Figure (1): Illustrates that; $42.4 \%$ of studied pregnant women had average knowledge about iodine deficiency and iodine supplementation during pregnancy, while $31.8 \%$ of them had poor knowledge about iodine deficiency and iodine supplementation during pregnancy and only $25.8 \%$ of them had good knowledge about iodine deficiency and iodine supplementation during pregnancy.

Figure (2): Shows that; $55.2 \%$ of pregnant women had unsatisfactory reported practices regarding prevention of iodine deficiency during pregnancy, while $44.8 \%$ of them had satisfactory reported practices regarding prevention of iodine deficiency during pregnancy.

Table (2): Reveals that; there was statistical significant relation between total knowledge score of studied pregnant women and their age and income, while there were no statistically significant relation between total knowledge score of studied pregnant women and their residence, level of education and occupation.

Table (3): Reveals that; there was no statistical significant relation between total reported practice score of studied pregnant women and their age, residence, level of education, occupation and income.

Table (4): Reveals that; there were statistically significant relation between total practice score of studied pregnant women and their total knowledge score. 
Table (1): Frequency distribution of studied pregnant women regarding their sociodemographic characteristics $(n=337)$

\begin{tabular}{|c|c|c|}
\hline Demographic characteristics & No. & $\%$ \\
\hline \multicolumn{3}{|l|}{ Age } \\
\hline$<20$ & 10 & 3.0 \\
\hline $20-<30$ & 220 & 65.3 \\
\hline $30-<40$ & 107 & 31.8 \\
\hline Mean \pm SD & \multicolumn{2}{|c|}{$31.2 \pm 5.22$} \\
\hline \multicolumn{3}{|l|}{ Residence } \\
\hline Rural & 205 & 60.8 \\
\hline Urban & 132 & 39.2 \\
\hline \multicolumn{3}{|l|}{ Education } \\
\hline Cannot read\& write & 51 & 15.1 \\
\hline Basic education & 126 & 37.3 \\
\hline Secondary education & 90 & 26.7 \\
\hline University and post graduate studies & 70 & 20.8 \\
\hline \multicolumn{3}{|l|}{ Occupation } \\
\hline Student & 33 & 9.8 \\
\hline House wife & 105 & 31.2 \\
\hline Employee & 199 & 59.1 \\
\hline \multicolumn{3}{|l|}{ Family income } \\
\hline Enough & 140 & 41.5 \\
\hline Not enough & 61 & 18.1 \\
\hline Enough and saving & 136 & 40.4 \\
\hline
\end{tabular}

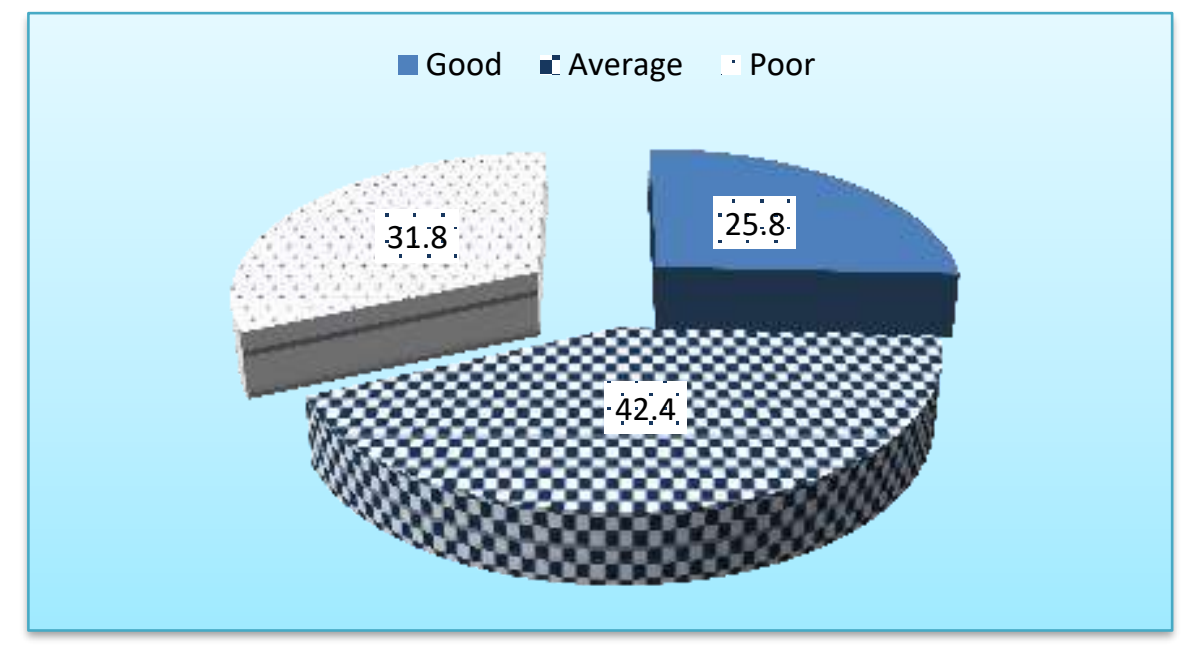

Figure (1): Percentage distribution of studied pregnant women regarding their total knowledge score $(n=337)$ 


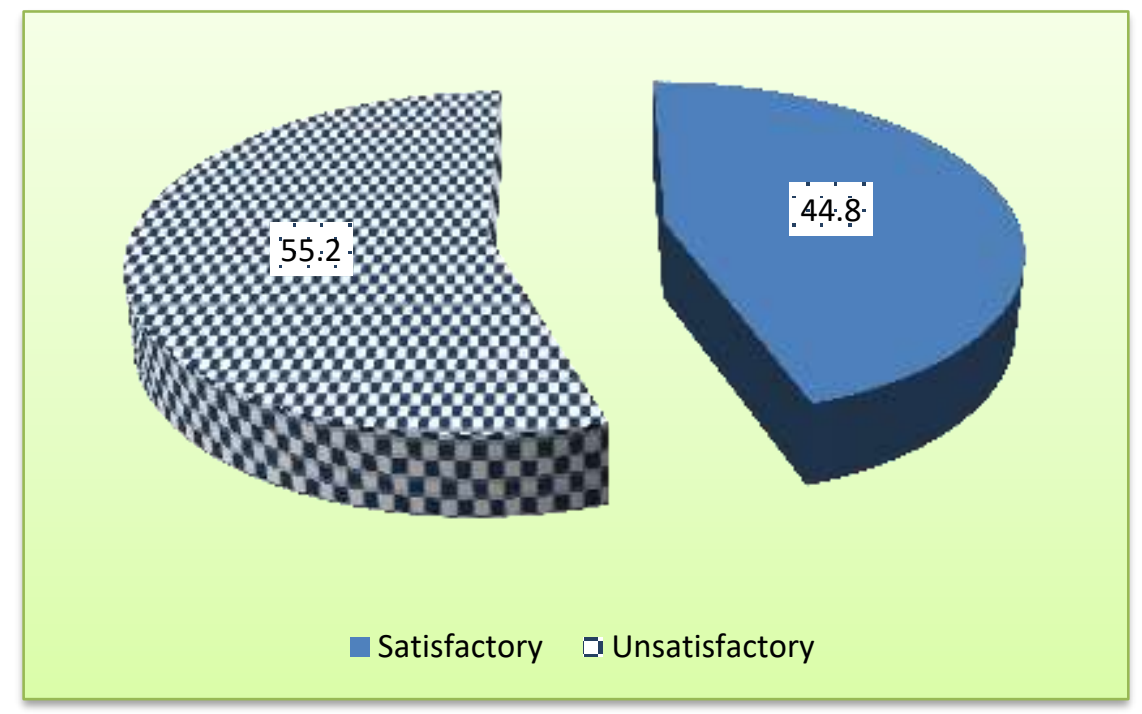

Figure (2): Percentage distribution of studied pregnant women regarding their total reported practices scores $(n=337)$.

Table (2): Statistical relation between socio-demographic characteristics of studied pregnant women and their total knowledge score $(n=337)$.

\begin{tabular}{|c|c|c|c|c|c|c|c|c|}
\hline \multirow[t]{2}{*}{ Items } & \multicolumn{2}{|c|}{$\begin{array}{l}\text { Poor } \\
(n=107)\end{array}$} & \multicolumn{2}{|c|}{$\begin{array}{l}\text { Average } \\
(\mathbf{n}=143)\end{array}$} & \multicolumn{2}{|c|}{$\begin{array}{l}\text { Good } \\
(\mathbf{n}=87)\end{array}$} & \multirow[t]{2}{*}{$\mathbf{X}^{2}$} & \multirow{2}{*}{$\begin{array}{l}p- \\
\text { value }\end{array}$} \\
\hline & No. & $\%$ & No. & $\%$ & No. & $\%$ & & \\
\hline \multicolumn{9}{|l|}{ Age } \\
\hline$<20$ & 0 & 0.0 & 5 & 3.5 & 5 & 5.7 & 10.623 & $.031 *$ \\
\hline $20<30$ & 71 & 66.4 & 86 & 60.1 & 63 & 72.4 & & \\
\hline $30<40$ & 36 & 33.6 & 52 & 36.4 & 19 & 21.8 & & \\
\hline \multicolumn{9}{|l|}{ Residence } \\
\hline Rural & 61 & 57.0 & 91 & 63.6 & 53 & 60.9 & 1.128 & 0.569 \\
\hline Urban & 46 & 43.0 & 52 & 36.4 & 34 & 39.1 & & \\
\hline \multicolumn{9}{|l|}{ Education } \\
\hline Cannot read and write & 15 & 14.0 & 23 & 16.1 & 13 & 14.9 & 0.431 & 0.98 \\
\hline Basic education & 70 & 65.4 & 30 & 20.9 & 26 & 33.3 & & \\
\hline Secondary education & 45 & 42.0 & 22 & 15.3 & 23 & 26.4 & & \\
\hline $\begin{array}{l}\text { University and high } \\
\text { education }\end{array}$ & 22 & 20.6 & 31 & 21.7 & 17 & 19.5 & & \\
\hline \multicolumn{9}{|l|}{ Occupation } \\
\hline Student & 13 & 12.1 & 13 & 9.1 & 7 & 8.0 & 1.257 & 0.869 \\
\hline House wife & 33 & 30.8 & 46 & 32.2 & 26 & 29.9 & & \\
\hline Employee & 61 & 57.0 & 84 & 58.7 & 54 & 62.1 & & \\
\hline \multicolumn{9}{|l|}{ Family income } \\
\hline Enough & 38 & 35.5 & 53 & 37.1 & 49 & 56.3 & 10.685 & $0.030 *$ \\
\hline Not enough & 22 & 20.6 & 27 & 18.9 & 12 & 13.8 & & \\
\hline Enough and save & 47 & 43.9 & 63 & 44.1 & 26 & 29.9 & & \\
\hline
\end{tabular}


Table (3): Statistical relation between socio-demographic characteristics of studied pregnant women and their total reported practices score $(n=337)$.

\begin{tabular}{|c|c|c|c|c|c|c|}
\hline \multirow{2}{*}{ Items } & \multicolumn{2}{|c|}{$\begin{array}{l}\text { Unsatisfactory } \\
\quad(n=186)\end{array}$} & \multicolumn{2}{|c|}{$\begin{array}{l}\text { Satisfactory } \\
\quad(n=151)\end{array}$} & \multirow{2}{*}{$\mathbf{X}^{2}$} & \multirow{2}{*}{ p-value } \\
\hline & No. & $\%$ & No. & $\%$ & & \\
\hline \multicolumn{7}{|l|}{ Age } \\
\hline$<20$ & 6 & 3.2 & 4 & 2.6 & 0.097 & 0.953 \\
\hline $20<30$ & 121 & 65.1 & 99 & 65.6 & & \\
\hline $30<40$ & 59 & 31.7 & 48 & 31.8 & & \\
\hline \multicolumn{7}{|l|}{ Residence } \\
\hline Rural & 113 & 60.8 & 92 & 60.9 & 0.001 & 0.974 \\
\hline Urban & 73 & 39.2 & 59 & 39.1 & & \\
\hline \multicolumn{7}{|l|}{ Education } \\
\hline $\begin{array}{l}\text { Cannot read } \\
\text { and write }\end{array}$ & 28 & 15.1 & 23 & 15.2 & 3.406 & 0.182 \\
\hline $\begin{array}{l}\text { Basic } \\
\text { education }\end{array}$ & 126 & 67.7 & 90 & 59.6 & & \\
\hline $\begin{array}{l}\text { University } \\
\text { and high } \\
\text { education }\end{array}$ & 32 & 17.2 & 38 & 25.2 & & \\
\hline \multicolumn{7}{|l|}{ Occupation } \\
\hline Student & 18 & 9.7 & 15 & 9.9 & 0.062 & 0.969 \\
\hline House wife & 59 & 31.7 & 46 & 30.5 & & \\
\hline Employee & 109 & 58.6 & 90 & 59.6 & & \\
\hline \multicolumn{7}{|c|}{ Family income } \\
\hline Enough & 73 & 39.2 & 67 & 44.4 & 0.995 & 0.608 \\
\hline Not enough & 34 & 18.3 & 27 & 17.9 & & \\
\hline $\begin{array}{l}\text { Enough and } \\
\text { save }\end{array}$ & 79 & 42.5 & 57 & 37.7 & & \\
\hline
\end{tabular}

Table (4): Statistically relation between total knowledge score and total reported practices score of studied pregnant women $(n=337)$.

\begin{tabular}{|l|l|l|l|l|l|l|}
\hline Total practice & \multicolumn{2}{|l|}{$\begin{array}{l}\text { Unsatisfactory } \\
(\mathbf{n = 1 8 6})\end{array}$} & \multicolumn{2}{l|}{$\begin{array}{l}\text { Satisfactory } \\
(\mathbf{n = 1 5 1})\end{array}$} & $\mathbf{X}^{2}$ & p-value \\
\hline Total knowledge & No. & $\%$ & No. & $\%$ & & \\
\hline Poor (n=107) & 67 & 36.1 & 40 & 26.4 & 7.171 & $.028^{*}$ \\
\hline Average(n=143) & 81 & 43.5 & 62 & 41.1 & & \\
\hline Good(n=87) & 38 & 20.4 & 49 & 32.5 & & \\
\hline
\end{tabular}




\section{Discussion:}

Iodine is an essential nutrient for the synthesis of thyroid hormones, which are critical to fetal brain development and metabolic processes in the body throughout life. Pregnant women and their offspring are especially vulnerable to the effects of iodine deficiency disorders. The demand for iodine intake is increased over $50 \%$ during pregnancy, and research has indicated that the first 1000 days of life (from conception up to 2 years of age) are crucial for the prevention of adulthood diseases (Yang et al., 2016).

Regarding to socio-demographic characteristics of the studied pregnant women, this study showed that less than two thirds of pregnant women aged from 20 to less than 30 years with mean age was 31.2. This finding was in the same line with Aakre et al., (2020), who studied "Iodine status during pregnancy and post-partum at four Norwegian health regions, Norway" $(n=1004)$, who found that the mean age of pregnant women was 30.2 \pm 4.8 .

Regarding to residence, less than two thirds of the studied pregnant women were from rural area. This finding disagreed with Torres et al., (2017), who performed a study on "Iodine nutritional status of women in their first trimester of pregnancy in Catalonia" $(n=1844)$, they found that $73.7 \%$ were from urban area.

Regarding to educational level, more than one third of studied pregnant women had basic education. This might be due to most of pregnant women were from rural area. This finding agreed with Ferede et al., (2018), who performed a study on "Knowledge and attitude about prevention of iodine deficiency disorder among women and quantification of iodide found in table salt in Central Highland of Ethiopia" ( $\mathrm{n}=1012$ ), they found that $38.7 \%$ of pregnant women had basic education. While this finding disagreed with Fereja et al., (2018), who studied a study on "Prevalence of iodine deficiency and associated factors among pregnant women in Ada district, Oromia region" $(n=356)$ reported that $45.0 \%$ of pregnant women were illiterate.

Regarding to occupation, more than half of the studied pregnant women were employee. This might be due to their need to improve standard of living. This finding was in the same line with Aakre et al., (2020), they found that $76.7 \%$ of pregnant women were employee. While this finding disagreed with Fereja et al., (2018), they found that nearly all $95.2 \%$ didn't work.

Regarding to family income, less than half of the studied pregnant women had enough monthly income. This might be due to that more than of pregnant women were employee. This finding agreed with Celik et al., (2016), who studied a study on "Iodine deficiency in pregnant women living in western Turkey (Edirne)" $(\mathrm{n}=275)$, who found that $44.7 \%$ of pregnant women had enough income.

Regarding to total knowledge of the studied pregnant women, less than half of pregnant women had average knowledge about iodine deficiency during pregnancy. This finding agreed with Khamsingnork et al., (2016), showed that $38.3 \%$ of pregnant women had average knowledge about iodine deficiency during pregnancy. While this finding disagreed with Khattak et al., (2018), who performed study on "Regional influences on nutritional iodine status of pregnant women in 
Pakistan"(n=1246), Showed that $87.7 \%$ of pregnant women hadn't knowledge about iodine deficiency during pregnancy.

Concerning to total reported practices, more than half of pregnant women had unsatisfactory reported practices regarding iodine deficiency during pregnancy. This finding agreed with Khamsingnork et al., (2016), who reported that the majority of pregnant women had unsatisfactory reported practices regarding iodine deficiency during pregnancy

The present study reveals that; there were statistically significant relation between total knowledge score of studied pregnant women and their age and income, while there were no statistically significant relation between total knowledge score of studied pregnant women and their residence, level of education and occupation. This finding agreed with Censi et al., (2019), who showed that no relation between knowledge of pregnant women and their education. While this finding disagreed with Nazli et al., (2020), who performed study on "The iodine knowledge of pregnant women in an endemic goiter Area, Trabzon, Turkey" ( $n=150)$, Showed that higher educated pregnant women had significantly higher knowledge scores However, age had no significant differences.

The present study reveals that; there were no statistically significant relation between total practice score of studied pregnant women and their age, residence, level of education, occupation and income. This might due to iodine is found in several foods and also found in cheap food as salt which may be used daily by pregnant women. This finding agreed with Brantsaeter et al., (2017), who performed study "Inadequate iodine intake in population groups defined by age, life stage and vegetarian dietary practice in a Norwegian convenience sample, Norway" $(n=276)$, reported that inadequate iodine intake had no relation with low-income.

There were statistically significant relation between total practice score of studied pregnant women and their total knowledge score. This might due to poor knowledge of iodine deficiency lead to poor practice. This finding agreed with O'Kane et al. (2016), who performed study on "Iodine knowledge is positively associated with dietary iodine intake among women of childbearing age in the UK and Ireland" $(\mathrm{n}=520)$, reported that there was a positive association between total daily iodine intake and total iodine knowledge score.

\section{Conclusion}

The study shows that less than two thirds of pregnant women aged 20years to less than 30 years, less than two thirds of pregnant women were lived in rural areas, and more than one third of them had basic education. Less than half of pregnant women had average knowledge about IDD, more than half of pregnant women had unsatisfactory reported practices regarding prevention of IDD during pregnancy. There were statistically significant relations between total knowledge score of pregnant women and their age and income. There were no statistically significant relations between total report practice score of pregnant women and their age, residence, level of education, occupation and income. There were statistically significant relation between total knowledge score and total reported practice score. 


\section{Recommendations}

1. Health educational program should be developed and implemented for pregnant women to educate them about meaning and the hazards of iodine deficiency during pregnancy.

2. Booklets and posters should be available and distributed in all maternal and child health care centers and in all hospitals to increase awareness of pregnant women about iodine deficiency during pregnancy and it's hazards and methods of prevention.

3. Further researches are needed to study the effect of IDD on physical and emotional health of pregnant women.

4. Regular periodic screening for all pregnant women for early detection of iodine deficiency disorders and providing management

\section{References}

Aakre, I., Strand, T., Moubarek, K., Barikmo, I., and Henjum, S. (2020). Associations between thyroid dysfunction and developmental status in children with excessive iodine status. Available at: https:Ilpubmed .ncb i.nlm.nih.gov. Accessed on 17 August/ 12 am.

Bonofiglio, D., and Catalano, S. (2020). Effects of Iodine Intake and Nutraceuticals in Thyroidology: Update and Prospects Available at: https: Iwww.ncbi.nlm.nih.gov. Accessed on $16 \mathrm{Feb} / 2 \mathrm{am}$.

Brantsæter, L., Knutsen, K., Johansen, C., Nyheim, A., Erlund, I., Meltzer, M., and Henjum, S. (2017). Inadequate Iodine Intake in Population Groups Defined by Age, Life Stage and Vegetarian Dietary Practice in a Norwegian Convenience Sample. Nutrients. doi: 10.3390/nu10020230. PMID: 29462974; PMCID: PMC5852806. Available at: https:Ilpubmed.ncbi.nlm.nih.gov. Accessed on 18 Nov $11 \mathrm{pm}$.

Celik, H., Guldiken, S., Celik, S., Taymez, F., Dagdeviren, N., and Tuğrul, A. (2016). Iodine Deficiency In Pregnant Women Living In Western Turkey (Edirne) This article has been cited by other articles in PMC. doi: 10.4183/aeb.2016.14. Available at: https:Ilpubmed.ncbi.nlm.nih.gov. Accessed on 19 Sep / 7 am.

Censi, S., Fernando, S., Groccia, G., Manso, S., Plebani, M., and Mian, C. (2019). The Effects of Iodine Supplementation in Pregnancy on Iodine Status, Thyroglobulin Levels and Thyroid Function Parameters: Results from a Randomized Controlled Clinical Trial in a Mild-to-Moderate Iodine Deficiency Area. Nutrients. 2019 Nov; 11(11): 2639. Available at: https:Ilpubmed.ncbi.nlm.nih.gov. Accessed on $19 \mathrm{Mar} / 7 \mathrm{am}$.

Diaz, E., Ortiz, J., Lee, S., Rodriguez, L., and Pearce, E.(2020). Iodine Status in Pregnant Women of Puerto Rico. Volume 27, ISSUE 3, P241-244, March 01, 2021. DOI :https://doi.org/10.1016/j $\quad$.eprac.2020.10.002. Accessed on $14 \mathrm{feb} / 6 \mathrm{pm}$.

Ferede, A., Abera, M., and Belachew, T. (2018). Knowledge and Attitude about Prevention of Iodine Deficiency Disorders (IDD) among Women and Quantification of Iodide found in Table Salt in Central Highland of Ethiopia Volume 12 - Issue2.Availableat: https:Ibiomedres .us. Accessed on 25 Mar\12pm. 
Fereja, M., Gebremedhin, S., Gebreegziabher, T., Girma, M., and Stoecker, J. (2018). Prevalence of iodine deficiency and associated factors among pregnant women in Ada district, Oromia region, Ethiopia: a cross-sectional study. BMC pregnancy and childbirth, 18(1), 1-8. Available at: https: Iwwww.ncbi.nlm.nih.gov. Accessed on 27 Marl1pm.

Ferguson, E., and Dimitri, P. (2018). The complications of a goitre secondary to iodine deficiency. DOI: 10.1530/endoabs .58.OC1.2. Available at at https: \\www.healthgrades.com. Accessed on 3 Mar 5 pm.

Gargari, S., Fateh, R., Bakhtiari, M., Saleh, M., Mirzamoradi, M., and Bakhtiyari, M. (2020). Maternal and neonatal outcomes and determinants of iodine deficiency in third trimester of pregnancy in an iodine sufficient area. BMC Pregnancy Childbirth20, 174 (2020).

Iodine Global Network (IGN). (2017). Global Scorecard of Iodine Nutrition in 2017 in the general population and in pregnant women (PW). Zurich, Switzerland: IGN; 2017. Accessed on 13feb /5 am.

Ivanova, L. (2015). Iodine Deficiency Disorders and Salt Iodization -Public Health Implications. J Nutr Health Food Eng. 2015; 2(1):1-2.7

Khamsingnork, J., Chongsomchai, C., Kuchaisit, C, and Lumbiganon, p.(2016). Knowledge, Attitude and Practice regarding Iodine Deficiency Disorder among Pregnant Women at Srinagarind Hospital, Khon Kaen, Thailand Thai Journal of Obstetrics and
GynaecologyOctober 2016, Vol. 24, pp. 255264.

Khattak, M., Saifullah, Z., Khadija, G., Fayyaz, A., Zaman, S., Gul, M., Khattak, K., Schauer, B., Völzke, H., and Ittermann, T. (2018). Regional Influences on Nutritional Iodine Status of Pregnant Women in Pakistan. Thyroid. 2018 Nov;28(11):1538-1546. doi: 10.1089/thy.2017.0267. PMID: 30311856. Available at: https: Ilpubmed.ncbi.nlm.nih.gov. Accessed on 12 April $\backslash 6 \mathrm{pm}$.

Kumar, P., Pattanaik, K., and Sood, K. (2020). Block-1 Population and Health Care. Available at: https: Ilwww.researchgate.com. Accessed on $28 \mathrm{Mar} / 4$ am

Nazli, N., Çin, A., and Özçelik, A. (2020). The Iodine Knowledge of Pregnant Women in an Endemic Goiter Area: A Cross Sectional Study. DOI: $10.21203 /$ rs.3.rs-26437/v1. Available at: https: Iwww.researchsquare.com. Accessed on 13Jan 12am.

O'Kane, M., Pourshahidi, K., Farren, M., Mulhern, S., Strain, J., and Yeates, J. (2016). Iodine knowledge is positively associated with dietary iodine intake among women of childbearing age in the UK and Ireland. $\mathrm{Br} \mathrm{J}$ Nutr. 2016;18:1-8.

Polonia, (2013). Analysis of sample size in consumer surveys GfK, Poland.

Ragab, M., Ali, S., and Tayel, D. (2019). Iodine Content in Commonly Consumed Egyptian Foods and Its Dietary Intake among Pregnant Women in Alexandria

Raman, R. (2017). 10 Signs and Symptoms of Iodine Deficiency. Available at https: Ilwww. healthline.com. Accessed on 1 Mar\} 2 \text { Am. } 
Torres, M., Francés, L., Vila, L., Manresa, M., Falguera, G., Prieto, G., and Casamitjana, M. (2017). Iodine nutritional status of women in their first trimester of pregnancy in Catalonia Open AccessBMC Pregnancy and Childbirthvolume 17, Article number: 249 (2017) Cite this article. Available at: https://www.biomedcentral.com. Accessed on 6 Dec 15 am

Yang, J., Zhu, L., Li, X., Zheng, H., Wang, Z., Liu, Y., and Hao, Z. (2016). Iodine status of vulnerable populations in Henan province of China 2013-2014 after the implementation of the new iodized salt standard. Biol. Trace Elem. Res. 2016, 173, 7-13. Available at: https://www.google.scholar.com. Accessed on 28Oct 15 am.

Zimmerman, M., and Boelaert, $\mathbf{K}$. (2015). Iodine deficiency and thyroid disorders. Lancet. 2015;3(4):286-295. Available at: https://pubmed.ncbi.nlm.nih.gov. Accessed on $11 \mathrm{Feb} / 11 \mathrm{pm}$. 


\section{معلومات وممارسات السيدات الحوامل تجاه الوقاية من نقص اليود اثناء الحمل}

$$
\text { وسام رمضان حسن- دعاء محمد صبحى السيد ـ هدية فتحى محى الدين. }
$$

يعتبر عنصر اليود من العناصر الغذائية الهامة لنمو الجسم، وتعتبر ظاهرة نقص اليود من المشاكل الغذائية عالميا لذلك يجب ان تكون السيدات الحوامل على دراية كاملة بطرف الوقاية من نقص اليود اثناء الحمل.لذلك هدفت هذه الدر اسة الى تقييم معلومات وممارسات السيدات الحو امل تجاه الوقاية من نقص اليود اثناء الحمل وقد اجريت هذه الدراسة بعيادة متابعة الحمل بالمركز الطبى جامعة بنها على Vسب سيدة حامل، حيث كثفت النتائج عن انه هناك علاقات ذات دلالة إحصائية بين مجموع معلومات السيدات وممارستهن. كما اوصت الدر اسة بتطوير وتنفيذ برنامج تعليمي صحي للسيدات لتثقفهن حول معنى ومخاطر نقص اليود اثناء الحمل وكما ان هنالك حاجة إلى مزيد من البحوث لدراسة تأثير نقص اليود على الحياة البدنية والنفسية للسيدات الحو امل. 